\title{
Market-based business model for flexible energy aggregators in distribution networks
}

\author{
J. Zupančič ${ }^{1}$, B. Prislan ${ }^{1}$, E. Lakić ${ }^{1}$, T. Medved ${ }^{1}$, A. F. Gubina ${ }^{1}$, A.Tuerk ${ }^{2}$, V. Kulmer ${ }^{2}$ \\ ${ }^{1}$ Laboratory of energy policy, Faculty of electrical engineering, University of Ljubljana, Slovenia \\ ${ }^{2}$ Joanneum Research, Graz, Austria \\ Jernej.Zupancic@fe.uni-lj.si
}

\begin{abstract}
The increasing rate of the smart technology implementations in the energy sector brings new control solutions for distributed renewable energy sources (DRES) to tackle the additional challenges on the distribution network that arise from increased integration of renewable energy sources (RES). With these new control solutions, a possibility of new services that could be offered on electricity and ancillary markets emerged, providing a possibility of new source of income for DRES, Demand Response (DR) and Aggregators. This paper presents the main results of the EU FP7 project INCREASE, where innovative controls for DRES and DR units were developed and investigated. The main novelty of the paper is a sensitivity analysis of INCREASE ancillary services and business model applied to representative European grid for overall policy conclusions. The knowledge gained in INCREASE provides the basis for the work in $\mathbf{H 2 0 2 0}$ project STORY, where the demand response strategies will be augmented to encompass small-scale storage solutions.
\end{abstract}

Index Terms - Aggregators business model, Demand response, Distributed renewable energy sources, Sensitivity analysis, Project INCREASE

\section{INTRODUCTION}

The integration of DRES units in the medium and low voltage (LV) distribution networks is forcing Distribution System Operators (DSOs) to continuously introduce new solutions and adapt the necessary changes in network operation. Higher penetration level of DRES is causing local surpluses of produced energy and as result reverse power flows occur in the network. The local power injection of DRES can lead to overvoltages and to current congestion on the network elements, such as transformer stations and overhead or cable lines, [1]. DRES in this research were limited to photovoltaic small-scale (PV) sources, heat pumps as the DR unit, with flexibility part of consumption, static part of consumption and defined time of use (TOU), where DR unit is available for scheduling.

In the INCREASE project, we have developed innovative solutions for control of DRES and DR units. They include advanced inverters for PVs [2], as well as the hierarchical multi-agent system (MAS) [3] for their control. The MAS consist of 3 levels of control where the first two are in charge of technical control through the smart inverter, while the third one represent the service layer. In the service layer, the INCREASE scheduling control makes the schedules for flexible energy sources, based on its optimization criteria, either maximizing the profit or minimizing energy differences between local production and consumption. The outcome of scheduling control highly depends on the system rules and boundary conditions, which include technical, economic, market, and regulatory provisions. These rules and boundary conditions define the framework that characterize each country in which the solutions are deployed.

This article will present the viability of the INCREASE solutions and key INCREASE Ancillary Services (AS) within the current framework conditions in the INCREASE partner countries. Previous assessments of INCREASE AS in [4], [5] were done on the low voltage (LV) grid of the Slovenian Distribution System Operator (DSO) Elektro Gorenjska. The main aim of the paper is to generalize the findings by assessment of INCREASE AS made on representative European grid as basis for overall policy conclusions. With purpose of application of INCREASE solutions within wider, EU region, data for European grid was gathered from several DSOs in central, southern and northern region.

The impact of INCREASE technologies was analysed using the scenario approach. INCREASE Value Analysis Methodology based on a technical analysis where MAS control strategy operation, [3], is simulated in a typical distribution network, using Evaluation Scenarios is described in [4], [5]. These evaluation scenarios cover the problem space in which MAS control operates, reflecting different operating stages of LV networks, e.g. with different penetrations rates of DRES and Demand Response or different seasons. The simulated outcomes of the MAS control strategies provide operating schedules of DRES- and DR-units and thus the 
physical properties of the four key INCREASE AS. Based on the technical analysis an economic, environmental and operation security assessment is made for different business cases that enables a broader view on possible benefits to the society than classical cost-benefit assessment. These assessments are made with the Value Analysis Tool (VAT) [4], a MATLAB based computing tool, created in INCREASE using Value Analysis scenarios defined in the project. These scenarios comprise a series of parameters that describe the assumptions used in our Value Analysis [5].

The rest of the paper is organized as follows. In section II, the INCREASE control strategies for smart inverter controls and multi agent scheme are described. In section III, we present our business model, where interactions between involved parties are described. In section IV the sensitivity analysis approach and parameters are given, while results and impact of parameters are presented in section V. Article concludes with summary of findings in section VI and future work in section VII.

\section{INCREASE CONTROL STRATEGIES}

In the selected business model with several actors, multiple INCREASE solutions were used. PV owners, DR units, DSO and Aggregator are part of proposed Multi Agent Scheme, which has defined hierarchal order of actions and position of the individual party as seen in Figure I.

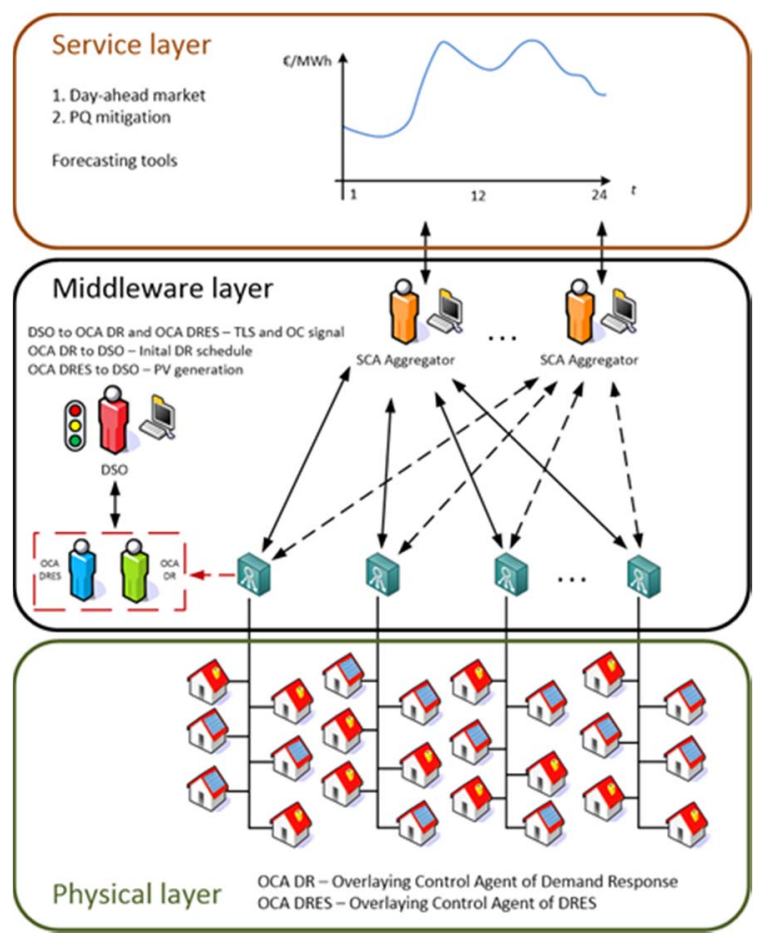

Figure I: INCREASE MAS control scheme

For the PV owners, two controls of inverters, located on physical layer, were compared from the economic point of view. The existing control, Simple Control ( $\mathrm{SiC}$ ), represents the inverter control before the implementation of the INCREASE solutions. The inverters are programmed to shut down the production of the PV unit, if the voltage level in the point of connection rises above upper threshold of $110 \%$ for nominal value or in per unit system - 1.1 p.u .

Through software upgrade of the inverter control, Local Control [7] (LC) of the inverter can be implemented to PV units. LC features droop control of production curve, which is triggered accordingly to the voltage levels of the local node or point of connection. Inverters starts gradually curtailing output of the PV plant at lower limit (1.06 p.u. was used as default value), which activates the control process and in case of reaching the upper limit (1.1 p.u.), the PV unit is shut down entirely. Local control provides a partial curtailment option, which allows higher level integration of PV production and lowers the amount of power quality violations in the network.

Scheduling control allows the aggregator to schedule the operation of DR units accordingly to an economic or a system oriented scheduling approach. It is located in highest, Service layer of MAS scheme. After the schedules for DR units in aggregator's portfolio are prepared, the DSO evaluates the impact of DR operation on the network conditions. With the INCREASE traffic light system (TLS) [8], DSO performs a suitability check of the proposed schedules, and decides whether schedules are acceptable or they interfere with security of operation in the network. In the INCREASE business model the Aggregator aggregates and manages both, the sales of PV generated energy and flexible energy products, offered by DR units.

Scheduling control, and the MAS control strategy is furthermore described in [3] together with the different optimisation methods of scheduling control [8]. The technical results of INCREASE controls are presented and evaluated in INCREASE Deliverables D5.1 [4] and D5.2 [5].

\section{PROPOSED BUSINESS MODEL}

\section{A. Actors}

Based on results of initial economic calculation, a new business model was selected, displayed on Figure II with the focus on improving the aggregators' conditions and profits. PV units are aggregated in the aggregators PV portfolio and their produced energy is sold on the wholesale market. The PV unit owners pay to the aggregator a contractual share $\varphi_{P V}$ of their market revenue for its service as a broker to provide them the access to the wholesale electricity markets. This share represents the cost of service of the Aggregator as it gives the PV market access and takes over all the market risks associated with selling the PV energy. PV owner's costs consists of upgrades of the inverter control which allows them to actively participate in Voltage control schemes and increase their energy production.

The profit of the i-th PV unit (1) PSPV is calculated as a sum of all energy produced by the $\mathrm{PV}$ unit $W^{a}{ }_{\mathrm{PV}}$ in interval $\mathrm{T}$, where $\mathrm{a}=\mathrm{EC}$ denotes economic and $\mathrm{a}=\mathrm{EN}$ energy based scheduling control (SC) optimization, multiplied by the appropriate market price $\mathrm{S}_{\mathrm{M}}$. The fixed PV unit costs $\mathrm{C}_{\mathrm{PV}}$ are subtracted, 
which represents annual maintenance and inverter upgrade cost [6].

$$
\begin{aligned}
P S_{P V}^{a}= & \sum_{i=1}^{N}\left(\left(1-\varphi_{P V}\right) \sum_{k=1}^{T} W_{P V i, k}^{a} \cdot S_{M k}-C_{P V i}\right), \\
& a \in\{E N, E C\}
\end{aligned}
$$

For the DR units in the aggregators' portfolio, the aggregator has to cover the costs of acquiring DR unit flexibility capability $\mathrm{C}_{\mathrm{DRe}}$. They include installation, operation and maintenance of the Advanced Metering Infrastructure (AMI, ADR box and the required communication equipment) and the availability fee payment to the DR unit owners. In addition to DR costs, the aggregator covers his own cost $\mathrm{C}_{\mathrm{SCA}}$, which represent his cost of software purchase and updates together with personnel and overhead costs. The revenue of the Aggregator (2) also includes the income $\mathrm{R}_{\mathrm{A}-\mathrm{DR}}$ stems from successful sales of Flexible Energy Products (FEP) on the wholesale electricity markets. The income $\mathrm{R}_{\mathrm{A}-\mathrm{DR}}$ is composed of the DR units' energy changes $\Delta W_{\mathrm{DR}}$ in a given time interval, and we assume that they are sold at the same market price $\mathrm{S}_{\mathrm{M}}$ in both directions (increase and decrease of consumption).

$$
\begin{aligned}
& P S_{S C A}^{a}=\varphi_{D R} \cdot \sum_{k=1}^{T} S_{M k} \sum_{i=1}^{N}\left|\Delta W_{D R i k}\right|+\varphi_{P V} \cdot \sum_{k=1}^{T} W_{P V i, k}^{a} \cdot S_{M k} \\
& -\sum_{i=1}^{N} C_{D \text { Re } i}-C_{S C A}
\end{aligned}
$$

Income from offering the flexible energy products on the market, which are gained via different DR schedule optimization are split between aggregator and DR unit owners. The DR unit owner revenues (3) are determined as share of entire revenues, gained with trading the flexible energy product on the market and availability cost.

$$
P S_{D R}^{a}=\left(1-\varphi_{D R}\right) \cdot \sum_{k=1}^{T} S_{M k} \sum_{i=1}^{N}\left|\Delta W_{D R k i k}\right|+C_{\text {availability }}
$$

Availability payment $C_{\text {availability }}$ is defined for each of the DR units as an access fee, paid from the aggregators side, as a fixed yearly amount for using the DR flexibility. It also serves as a compensation tool in case of negative revenues from selling DR energy products on market, where aggregator has to cover the losses of DR unit in order to keep them in portfolio. For the economic evaluation, some of the assumptions were updated with latest values we received from market actors, and are described in following chapter of Value analysis assumptions.

Relative and absolute profitability of the aggregator was determined for both cases of operation: joint PV and DR unit portfolio and DR unit aggregation only. Initial set of results for value analysis showed, that implementation of availability fee paid by aggregator to DR unit owners, set the DR unit in positive orientation of the profits, but the aggregators expenses exceeds his income from selling DR FEP on wholesale market. Because the difference between high rate and the low rate of electricity price is relatively low, his income from selling DR energy products on wholesale is too low. This conforms to the market reality as the aggregator usually offers his services on reserve or balancing market, where prices are higher.

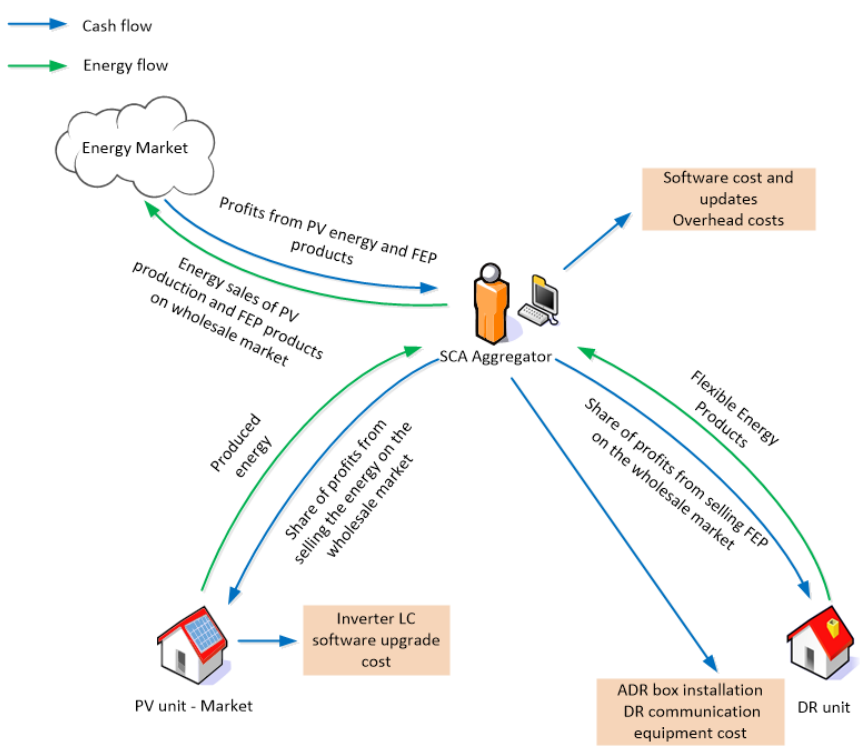

Figure II: Proposed business model

\section{B. Business model assumptions}

We have compiled a list of assumptions for the cost of PV inverter upgrades, DR unit equipment and cost related to aggregators business. The cost of upgrading the inverter to enable INCREASE local control are given in Table I.

Table I: PV owners cost

\begin{tabular}{|l|l|}
\hline Type of cost & Expense \\
\hline $\begin{array}{l}\text { Cost of inverters SW upgrade } \\
\text { [per 7kW inverter] }\end{array}$ & $150 €$ \\
\hline $\begin{array}{l}\text { Installation fee for the upgrade } \\
\text { per PV plant }\end{array}$ & $500 €$ \\
\hline Yearly maintenance cost & $3 €$ \\
\hline
\end{tabular}

For the PV inverters and DR equipment, 25 years' technical lifetime was defined, and annuity was defined with yearly interest rates of $2.5 \%$. Cost, which are present for the integration of the DR units to the MAS scheme of operation are given in Table II.

Table II: DR unit equipment cost

\begin{tabular}{|l|c|}
\hline Type of cost & Expense (€) \\
\hline DR unit communication cost & 500 \\
\hline Installation fee for the upgrade of DR unit & 200 \\
\hline Yearly maintenance cost & 1 \\
\hline
\end{tabular}




\section{Availability fee}

600

In Table III, aggregator's costs are presented, related to his operation. He has to buy software in order to operate, which is annually updated, and depending on the unit pool size of aggregation, several employees together with overhead costs are taken into consideration. When our initial sensitivity analysis were performed, the results indicated the fact, that annual expenses, such as yearly maintenance costs does not affect the results of the weekly calculations significantly and were set to marginal values, but since they can vary from country to country, they were included in the calculations.

Table III: Aggregator's business cost

\begin{tabular}{|l|l|}
\hline Type of cost & Value \\
\hline Aggregator's software cost & $100000 €$ \\
\hline Cost of SW update per year & $200 €$ \\
\hline Technical lifetime of software & 25 years \\
\hline Personnel cost per year & $50000 €$ \\
\hline $\begin{array}{l}\text { Overhead cost per year }(50 \% \text { of } \\
\text { personnel cost) }\end{array}$ & $25000 €$ \\
\hline
\end{tabular}

The number of personnel, which is employed by the aggregator, varies with the size of the aggregators' pool and the level of penetration (scenario). For PV the number of units reach up to 20,000 in the biggest pool size for DR. Heat pumps, used for the DR unit model, have $7.5 \mathrm{~kW}$ peak power rate, and were used in simulations along with $20 \mathrm{kWp} \mathrm{PV} \mathrm{rooftop}$ installations. The chosen cost structure is of high importance from the subsequent assessments; we assume that the aggregator starts its business based on INCREASE solutions, with corresponding personnel or overhead cost. In smaller pool sizes and lower levels of penetration, the aggregator's costs per $\mathrm{DR}$ in his portfolio increases as the investment is divided between fewer units.

\section{SENSITIVITY ANALYSIS}

In sensitivity analysis, which was in the part of the value analysis, specific parameters were varied in order to determine the business impact of the actors involved in business model. Variation impact of the aggregator's software cost, personnel cost and availability fees were investigated along with electricity price changes in the wholesale electricity market. Electricity prices were taken from Slovenian BSP Southpool Regional Energy Exchange [6]. Parameters, which are defined in business model and determine the profit sharing between the actors, were also checked together with the size of aggregation pool and its business. Parameters and their variations are given in Table IV, where bold values represent initial value of parameter used for the calculations in variations of other parameters.

The linear factor was determined with acquisition of three set of values for each parameter. For further extrapolation of the results, greater variation range was required and applied where it was necessary.

Table IV: Sensitivity analysis parameters

\begin{tabular}{|l|l|}
\hline Parameter & Variation range \\
\hline Energy price & $\mathbf{1 0 0} \%, 200 \%, 300 \%$ \\
\hline Agg. share from PV sales & $10 \%, \mathbf{2 0} \%$ to $30 \%$ \\
\hline Agg. share from DR sales & $35 \%, \mathbf{5 0} \%, 75 \%$ \\
\hline Agg. SW cost $[€]$ & $50000,75000, \mathbf{1 0 0} \mathbf{0 0 0}$ \\
\hline Agg. DR pool size & $100,1000, \mathbf{1 0} \mathbf{0 0 0}$ \\
\hline Availability fee per DR unit $[€]$ & $300, \mathbf{6 0 0}, 900$ \\
\hline
\end{tabular}

V. RESULTS

Technical simulations performed on representative synthetic grid, which was designed with information collected from several European DSOs [9], are shown in Figure III. Low voltage distribution network was subject of scenario approach analysis, where penetration level of PV and DR technology in the network was defined in scenarios defined in Table V, [6].

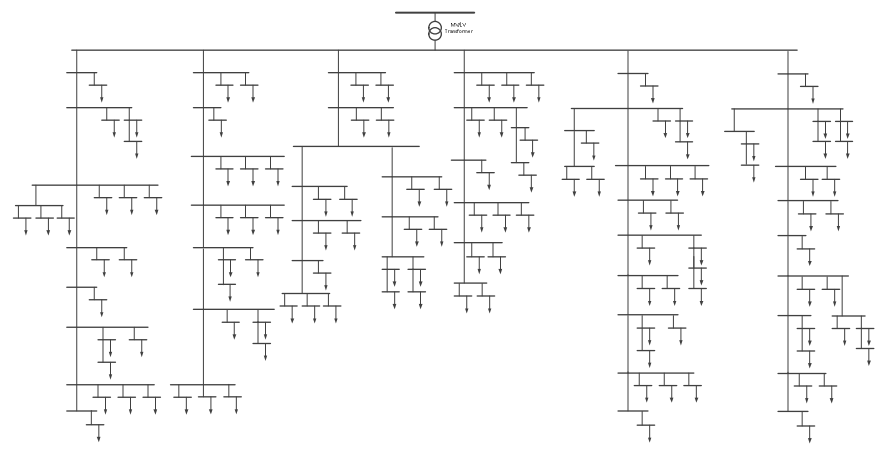

Figure III: LV distribution network topology

Table V: Penetration scenarios

\begin{tabular}{|c|c|c|c|c|}
\hline \multirow{2}{*}{ Scenario } & \multicolumn{2}{|l|}{ PV units } & \multicolumn{2}{l|}{ DR units } \\
\cline { 2 - 5 } & Number & $\begin{array}{l}\text { Capacity } \\
(\mathbf{k W})\end{array}$ & Number & $\begin{array}{l}\text { Capacity } \\
\text { (kW) }\end{array}$ \\
\hline 1 & 12 & 240 & 6 & 42 \\
\hline 2 & 24 & 480 & 12 & 84 \\
\hline 3 & 36 & 720 & 18 & 126 \\
\hline 4 & 48 & 970 & 24 & 168 \\
\hline 5 & 60 & 1200 & 30 & 210 \\
\hline
\end{tabular}

Results of the technical simulations, which consist of production profiles for PV units and schedules of operation for DR units, were used as an input for economic analysis. For the representation of the entire aggregator's portfolio, an assumption was made that all aggregator's units are operating 
under same conditions as units in this network. Aggregator's business comprises of selling PV energy on the electricity markets along with scheduling of the DR units in own portfolio in accordance with different optimization criteria - market based or more utility oriented scheduling. Our research was focused on Day-ahead wholesale market sales, where aggregator is selling and buying energy and energy products under varying market conditions.

\section{A. Impact of the market price}

In Figure IV a market price variation impact is presented for the default pool size, which contains of 10000 DR units and 20,000 PV units in the aggregators portfolio. Low penetration scenario ( $\mathrm{SC} 1$ ) give us the lowest profit due to the distribution operation cost of aggregators, which operates with fewest number of units. In highest penetration scenario (SC5) cost are distributed among large number of units, which produce higher profits. With increase of market price, the units in their pool produce additional $0.10 € / \mathrm{kW}$ to $15 € / \mathrm{kW}$ in one week of operation.

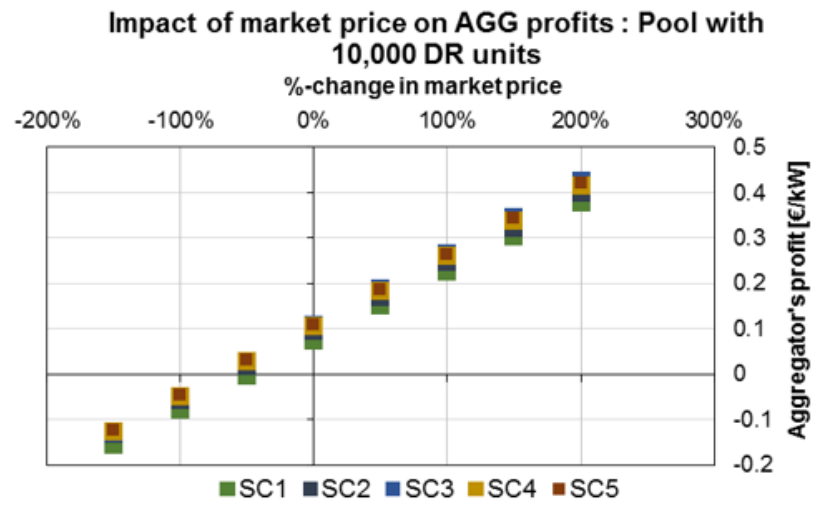

Figure IV: Impact of electricity price

\section{B. Aggregator's pool size}

The number of units in aggregator's portfolio is one of the most important factors for profitability of the business. With smaller pool size, income decreases, while costs of aggregators operation remain at the same level. In Figure V we witness that weekly operation costs are significantly larger in pool size of 100 DR and $200 \mathrm{PV}$ units in comparison with case of 1000 DR units and $2000 \mathrm{PV}$ units. In that case achieved profits in scenario with higher penetration levels are higher for current electricity wholesale prices. In addition to that fact, the biggest pool option always gain profit.

\section{Aggregators' share from $P V$ revenues}

Aggregator receives a service fee proportionally to the negotiated share from sold PV energy on the wholesale market. On Figure VI, the impact of percentage, which he receives is variated. Aggregator does not have direct cost with PV equipment or installation and his profits are mostly created from income of energy sales and increase significantly with higher percentage of received fee.

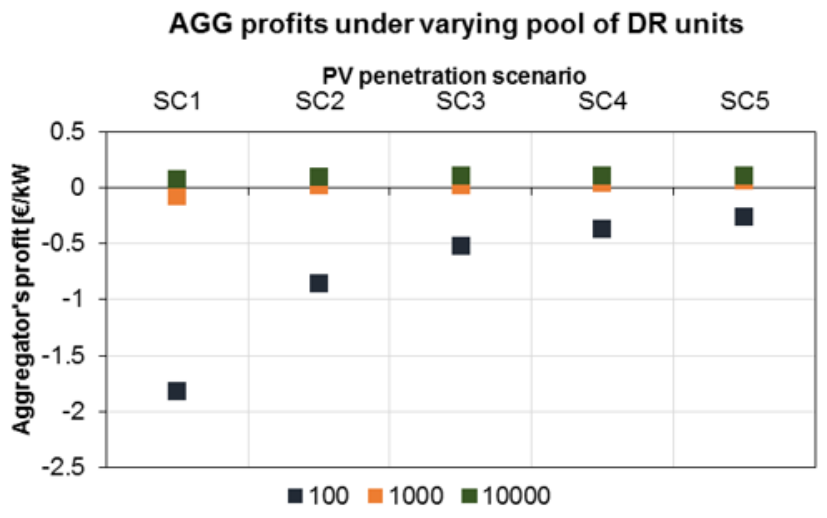

Figure V: Impact of aggregator's pool size on the profits

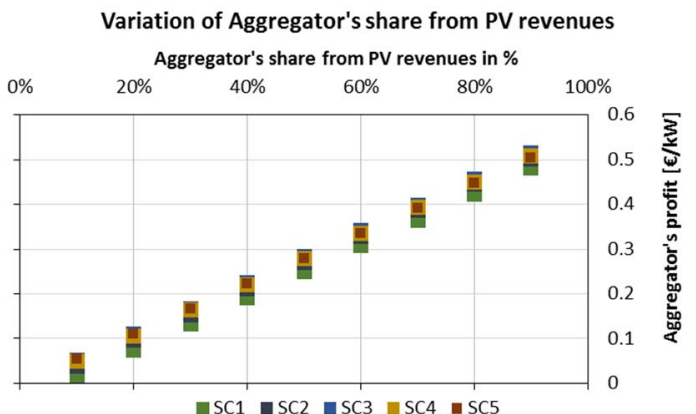

Figure VI: Impact of aggregators PV revenues share variation

\section{Aggregators' share from $D R$ reveneues}

Aggregator's profit decreases significantly if business portfolio includes only DR units. If market oriented scheduling optimization for units in his portfolio is chosen, the profit is gained from selling DR unit's energy when prices are higher and consuming when prices are lower. Due to small differences between the highest and lowest electricity price at the market, the incomes are lower, but for the bigger pools and higher penetration scenarios business is still profitable. In Figure VII we observe the change on aggregators profit if we variate the percentage, which he receives from trading with $D R$ unit's flexibility on the wholesale market. In comparison with previous case shown in Figure IV, the proposed business case is aggregation only and gain profits from 0.06 to $0.12 € / \mathrm{kW}$ on a weekly basis for default share of $50 \%$ DR revenue share as opposed to previous weekly profits in range of 0.2 to $0.3 € / \mathrm{kW}$.

\section{CONCLUSION}

This paper presents methodology and the results of analysis for viability of the INCREASE solutions used in the current market situation. An assessment for a representative European grid gives the possibility to present general findings, which can be used for policy adjustments. Aggregator's business case, with implemented INCREASE solutions, yields positive profits and presents viable business model. The size of aggregators pool determines the success of the business, mainly due to the distribution of own cost among sufficient DR units in his pool. 


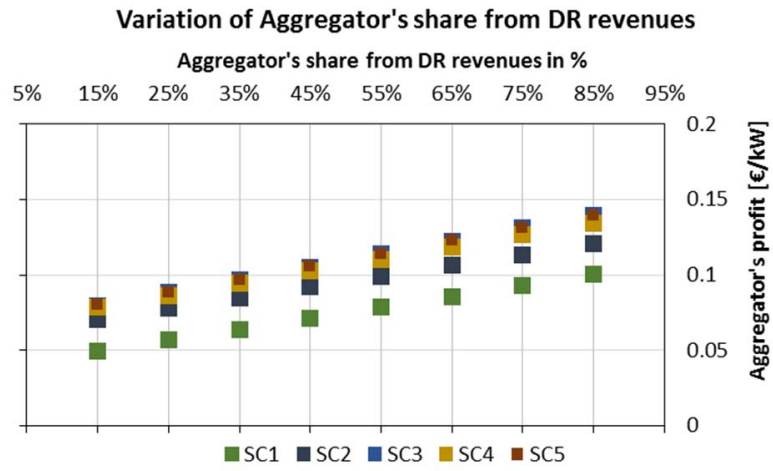

Figure VII: Impact of aggregators share from DR revenues

In business case of pool size 10000 aggregated DR units, the costs are spread across enough units to achieve positive profit in the operation.

Scenarios with lower level of penetration of PV and DR are less profitable or with even negative incomes for the cases of smaller aggregator's pool size, where the business is profitable only with increased energy prices or including the PV units. Higher level of penetration and utilization of aggregators' equipment ensures better cost distribution and better business conditions. Since low electricity wholesale market prices rarely bring some profit, the aggregator should focus his business to offers flexibility on other markets, namely the reserve market. Due to high cost for establishment of aggregators business, smaller pool sizes below 1000 units are hardly profitable. Aggregator needs to provide flexibility on reserve market; the availability payments to DR need to be low and the share of profits they get from the aggregator also needs to be low. For case of aggregating PV units in aggregator's business case, smaller pools are already profitable. This means that for smaller aggregators it is important to include PV or other DRES in their aggregation portfolio.

In our case the cost assumptions for the aggregator were based on the assumption of starting the aggregator business from scratch. If we consider already established companies, energy retailers or other entities, their transition to aggregation business and associated costs may be much lower and therefore small DR pools may become profitable. Currently the aggregator needs to secure the flexible energy product in capacity above $1 \mathrm{MW}$ in order to participate on reserve market. With possible restructure of the electricity market, smaller flexible products could also appear as valid business case and profitable option of aggregation. New market actors with their diverse business portfolios present possible impactful factors and will define the shape and structure of future electricity markets.

\section{FURTHER WORK}

The methodology that was developed and used in INCREASE Value Analysis approach and evaluation of the results, presents the basis for research in the $\mathrm{H} 2020$ project STORY, [10]. In STORY, the research focuses on the benefit of energy storage, monitoring of implemented technologies and evaluation of the impact of storage in the distribution networks, micro grids and industrial networks. Harvesting results from several demonstration sites, large-scale roll-out simulations and economic evaluation, future business models will be developed. STORY draws on the knowledge gained in INCREASE. In particular, the synthetic grid modelling approach, Value Analysis Tool and Ancillary Service provision options will be translated and applied to the storage technology, as an upgrade of the aggregator's portfolio.

\section{ACKNOWLEDGMENT}

This work was partially supported by the EU $7^{\text {th }}$ Framework Programme, grant agreement No. 608998, project INCREASE and the European Union's Horizon 2020 research and innovation programme, grant agreement No. 646426, project STORY.

\section{REFERENCES}

[1] INCREASE Project, "Report on relevant experiences," Deliverable D1.1, February 2014.

[2] INCREASE Project, "Fast control strategy for three-phase four-wire inverter for DRES", Deliverable D2.4, October 2014.

[3] INCREASE Project, "Optimal coordinating strategies to harmonise multi services/objectives" Deliverable D3.4, October 2015

[4] INCREASE Project, "Report on common definition of Ancillary Services in the Transmission system and in the Distribution system", Deliverable D5.1, October 2015

[5] INCREASE Project, "Report on short-term market mechanisms for AS provision," Deliverable D5.2, 2016

[6] INCREASE Project, "Report on necessary adjustments to the Regulatory framework", Deliverable D5.3, June 2016

[7] Ali, MM Mansoor Viyathukattuva Mohamed, et al. "Fair power curtailment of distributed renewable energy sources to mitigate overvoltages in low-voltage networks." PowerTech, 2015 IEEE Eindhoven. IEEE, 2015.

[8] A. Gubina, T. Medved: "A Method for Optimal Schedule Balancing in Distribution Network using Multi Agent Control Strategy", EEM 2016, Porto, Portugal, June 2016

[9] STORY project, "Selection of cases", Deliverable D7.1, May 2016

[10] “STORY project” [Online] Available: http://horizon2020story.eu/. 